\title{
Knowledge about first aid, wound management and vaccination for the cases of dog bite: a cross-sectional study among the students of a management and technology institute in western Uttar Pradesh
}

\author{
Anuj Singh, Medhavi Agarwal*, Arun Singh, Rashmi Katyal, H. S. Joshi, Swati Khan
}

Department of Community Medicine, Rohilkhand Medical College and Hospital, Bareilly, Uttar Pradesh, India

Received: 14 November 2017

Accepted: 04 December 2017

\section{*Correspondence:}

Dr. Medhavi Agarwal,

E-mail: dr.medhaviagarwal@gmail.com

Copyright: (C) the author(s), publisher and licensee Medip Academy. This is an open-access article distributed under the terms of the Creative Commons Attribution Non-Commercial License, which permits unrestricted non-commercial use, distribution, and reproduction in any medium, provided the original work is properly cited.

\begin{abstract}
Background: About half the world's population is living in countries/territories where dog rabies still exists and is potentially exposed to rabies. In 2005 there were 12,700 symptomatically identifiable furious rabies deaths in India; taken as a whole 1.1 deaths per lac population; mostly in males $(62 \%)$, in rural areas $(91 \%)$, and in children below the age of 15 years $(50 \%)$. The aims and objectives of the study were to ascertain the knowledge about the first aid and vaccination measures and to assess the awareness about management, dressing and suturing of wound following dog bite among students of a management college in the Western Uttar Pradesh.

Methods: A cross sectional study was conducted in a professional institute of Bareilly district selected by simple random sampling between August 2016- January2017, data was collected with the help of a questionnaire related to the assessment of knowledge regarding wound management.

Results: $96 \%$ believe in proper wound management of animal bite, 37\% think dressing of wound is necessary, $40 \%$ think immediate suturing of wound is important, where as $90 \%$ study subjects were aware of Anti-rabies vaccine.

Conclusions: Awareness assessment about the wound management is almost satisfactory. Since, majority of subjects know the right measure of first-aid and believe in proper wound management after dog bite along with the knowledge about anti-rabies vaccine.
\end{abstract}

Keywords: Wound management, Rabies, Students

\section{INTRODUCTION}

Rabies is an enzootic and epizootic disease of worldwide importance. In India, rabies is a zoonotic problem of considerable magnitude. Annual mortality more than 30,000 reported by national authorities may not be a complete picture because, since 1985 India continues to report the same every year. ${ }^{1}$ It is estimated that number of deaths due to rabies may be 10 times more than those reported. Every year approximately 1.1 to 1.5 million people are receiving post exposure prophylactic treatment. Although 2 million bites occur each year in India more than $95 \%$ of these cases are bitten by dogs. ${ }^{2}$

The irony is that most of the death occurs due to ignorance about urgency of "First-Aid management" of the wound after dog bite and lack of access to affordable and effective services in Health sector. ${ }^{3}$ There are many myths and false beliefs associated with wound management. These include application of oils, herbs, and red chilies on the wounds inflicted by rabid animals. More faith in indigenous medicines that are of unproven efficacy and not washing the wound properly because of 
fear that it would get infected. ${ }^{4}$ Human exposures to any form of dog bite weather lick/scratch with or without bleeding carries risk of rabies and hence need of vaccination. ${ }^{3}$ Every instance of dog bite should be treated as medical emergency. Prompt and adequate local treatment along with post-exposure prophylaxis is an effective way by which Rabies can be prevented. ${ }^{5}$

However, lack of awareness about the action to be taken following dog bite make the victim of dog bite vulnerable to risk of rabies. Beside the misconceptions associated with the wound management make the patient further vulnerable. The present study is an attempt to assess the extent of awareness among the management students about the dog bite first-aid wound management. The purpose of selecting the students of a management institute is that the college is situated in the rural areas which are overcrowded by street dogs. The habitants are vulnerable to the dog bites frequently and such victims often contacts to the students of higher institute. Since, they considered them most educated person in their locality who can tell about right measures to be followed after dog bite. In this context the present was conducted with following objectives.

\section{Objectives}

1. To ascertain the first aid measures adopted by people followed by animal/dog bite.

2. To assess the general awareness about wound management, dressing and suturing of wound following animal bite.

3. To ascertain knowledge about anti-rabies vaccine.

\section{METHODS}

This cross sectional study was conducted in the field practice area of Rohilkhand Medical College and Hospital, Bareilly district Uttar Pradesh. For the period of 6 months from August 2016 to January 2017. After taking the institutional ethical committee clearance. One of the management colleges was selected incatchment area of Rural Health and Training Centre (RHTC), Rithora by simple random sampling technique. Sample size was calculated, taking into consideration major study variables. The highest sample size was obtained for awareness about anti-rabies vaccination, first aid and wound management of dog bite. A total of 200 students were surveyed and initially explained regarding the purpose of the study. Details regarding the perceptions of rabies wound management and post exposure prophylaxis were obtained in a pretested structured perform a by interview technique. After collection, data was checked, verified, cleaned entered into SPSS program version -23 in the computer. The result was displayed with the help of tables according to the objectives of the study. Chisquare test was used for statistical interpretation of results.

\section{RESULTS}

Total 200 participants were included in the study. 88 were females $(44 \%)$ and the rest where males $(56 \%)$. First-aid following dog bite out of 200 study participants.

Table 1: Knowledge about first-aid following animal/dog bite.

\begin{tabular}{|ll|}
\hline First-aid following dog bite & Percentage (\%) \\
\hline Nothing & 4 \\
\hline $\begin{array}{l}\text { Herbal medicine (Turmeric, } \\
\text { chilly etc.) }\end{array}$ & 26 \\
\hline Wash with soap and water & 67 \\
\hline Dressing & 3 \\
\hline
\end{tabular}

Table 1 shows that $4 \%$ believe in doing nothing following dog bite. $26 \%$ believes in application of herbal medicines (chilly, turmeric etc.). $3 \%$ thinks that immediate dressing of the wound is necessary. Whereas majority of study participants $67 \%$ know the right the right method of first aid measure i.e. immediate washing of wound with soap under running tap water following the dog bite.

Table 2: Knowledge about wound management following animal/dog bite.

\begin{tabular}{|ll|}
\hline Dog-bite knowledge assessment & Percentage (\%) \\
\hline $\begin{array}{l}\text { Think dressing of wound is } \\
\text { necessary }\end{array}$ & 37 \\
\hline $\begin{array}{l}\text { Think immediate suturing of } \\
\text { wound is important }\end{array}$ & 40 \\
\hline $\begin{array}{l}\text { Believe in proper wound } \\
\text { management of dog/animal bite }\end{array}$ & 96 \\
\hline $\begin{array}{l}\text { Knowledge about anti rabies } \\
\text { vaccine }\end{array}$ & 90 \\
\hline
\end{tabular}

Table 2 determines that dog bite knowledge assessment reveals that $96 \%$ believe in proper wound management of animal bite, $37 \%$ think dressing of wound is necessary, $40 \%$ think immediate suturing of wound is important. Whereas $90 \%$ study subjects were aware of anti-rabies vaccine.

Table 3: Relationship between students of different courses and their knowledge related to first-aid wound management following dog/animal bite and chances of survival.

\begin{tabular}{|lllll|}
\hline Characteristics & $\begin{array}{l}\text { Chi- } \\
\text { square test }\end{array}$ & df & $\begin{array}{l}\text { P } \\
\text { value }\end{array}$ \\
\hline A) & $\begin{array}{l}\text { Knowledge about } \\
\text { first-aid following } \\
\text { dog/animal bite }\end{array}$ & 15.853 & 6 & 0.015 \\
\hline B) & $\begin{array}{l}\text { Knowledge about } \\
\text { chances of survival } \\
\text { if rabies developed }\end{array}$ & 28.114 & 6 & 0.00 \\
\hline
\end{tabular}


Table 3 shows the association between the various study fields (B. Ed, M. Ed, and BTC.) and their knowledge about first-aid following dog/animal bite. In association it was found that maximum students who know the right measure of first-aid following dog bite (i.e. immediate washing of wound with soap \& water) were pursuing B. Ed course (i.e. $78.66 \%$ ) This association was found to be statistically significant $(\mathrm{p}<0.05)$.

In the same table, part B shows the association between the various study fields and their Knowledge about chances of survival if rabies developed. In association it was found that maximum numbers of students who believe that chances of survival with rabies is possible were belongs to B. Ed category. This association was found to be statistically significant $(\mathrm{p}<0.05)$.

Table 4: Relationship between students of different courses with.

\begin{tabular}{|lllll|}
\hline Characteristics & $\begin{array}{l}\text { Chi- } \\
\text { Square } \\
\text { Test }\end{array}$ & df & $\begin{array}{l}\text { P } \\
\text { value }\end{array}$ \\
\hline A) & $\begin{array}{l}\text { Believe in proper } \\
\text { wound management of } \\
\text { dog/animal bite }\end{array}$ & 10.0007 & 2 & 0.007 \\
\hline B) & $\begin{array}{l}\text { Thinking about } \\
\text { dressing of wound is } \\
\text { necessary }\end{array}$ & 13.269 & 2 & 0.001 \\
\hline C) & $\begin{array}{l}\text { Thinking about } \\
\text { immediate suturing of } \\
\text { wound is important }\end{array}$ & 7.443 & 2 & 0.024 \\
\hline
\end{tabular}

$\mathrm{A}=$ Believe in proper wound management; $\mathrm{B}=$ Thinking about dressing of wound is necessary; $\mathrm{C}=$ Thinking about immediate suturing of wound is important.

Table 4 Part A Shows the association between the various study fields and their knowledge about first-aid following dog/animal bite. In association it was found that maximum participants who said that no first-aid is required were pursuing bed (i.e. 73.84\%). This association was found to be statistically significant $(\mathrm{p}<0.05)$.

Part B shows the association between the various study fields and they believe about dressing of wound. In association it was found that maximum participants who said that dressing of wound is not necessary were belongs to B. Ed category (i.e. 36.29\%) This association was found to be statistically significant $(\mathrm{p}<0.05)$

In the same table part $\mathrm{C}$ shows the association between the various study and their thinking about immediate suturing of wound. In association it was found that maximum students who thinks immediate suturing of wound is not necessary were also pursuing B. Ed course (i.e. $79.10 \%$ ). This association was found to be statistically significant $(\mathrm{p}<0.05)$.

\section{DISCUSSION}

In our study, dog bite knowledge assessment reveals that $96 \%$ of participants believe in proper wound management of animal bite, $37 \%$ think dressing of wound is necessary, $40 \%$ think immediate suturing of wound is important. Whereas $90 \%$ study subjects were aware of Anti-rabies vaccine. First-aid following dog bite out of 200 study participants, $4 \%$ believe in doing nothing following dog bite and $26 \%$ believes in application of herbal medicines (chilly, turmeric etc.). $3 \%$ thinks that immediate dressing of the wound is necessary. Whereas majority of study participants $67 \%$ know the right the right method of first aid i.e. immediate washing of wound with soap under running tap water following the dog bite. Knowledge about correct wound management was found to be adequate among respondents in our study. As $96 \%$ of the respondents had correct knowledge about toileting of wound with soap and water.

Similar finding was reported by Valekar et al from Maharashtra where majority proportion (45\%) of respondents being aware of correct wound toileting practice with soap and water. ${ }^{6}$

Different studies from India also reported belief on local application of chilies, oil, turmeric etc. over wound similar to our study. ${ }^{7-9}$ Therefore, awareness regarding correct first aid measures for the care of wound following animal bite should be strengthened among the general population.

\section{CONCLUSION}

Awareness assessment about the wound management is almost satisfactory. Since, majority of subjects know the right measure of first-aid and believe in proper wound management after dog bite along with the knowledge about anti-rabies vaccine. But, there is considerable percentage $(40 \%)$ of students who think immediate suturing of wound is important. Therefore, sensitization of young generation timely needed, So that their knowledge can be enhanced and their positive attitude can be further translated into proper practices for prevention and control of Rabies.

Our study provided an insight into the awareness and practice of the population regarding wound management following animal bites. Further research need to be carried out with a larger sample to explore the factors affecting poor wound care knowledge and practice. However, it was encouraging to note that majority of the study participants were aware regarding the correct measure to be followed after dog bite. The current study indicate the need for timely sensitization about the rabies prevention by use of mass media to spread awareness via posters, pamphlets, television, radio etc. locally specific IEC campaigns. Awareness about first aid \& importance 
of washing the wound site with water and soap is the most important message. Health education through antirabies campaigns must be provided to the community. Community people also need to be motivated to bring about positive attitude and awareness about the importance of consulting a qualified medical practitioner and vaccination to prevent and control from rabies.

\section{Strength of the study}

We are yet to find any publication that reported community based data on the actual magnitude of dog bite and health utilization in this part of India.

\section{Limitation of the study}

Firstly, smaller sample size; a larger sample size could have provided more precise information. Secondly, there was scope of recall bias that may have influenced the outcome analysis.

\section{ACKNOWLEDGEMENTS}

I thank the Head of Department of Community Medicine for giving me the opportunity to carry out the present study. I also thank all the participants who took part in the study to make this piece of research a success.

Funding: No funding sources Conflict of interest: None declared

Ethical approval: The study was approved by the Institutional Ethics Committee

\section{REFERENCES}

1. Goa Health News: Survey on rabies deaths in Goa. The Navhind Times April 13, 2003 issue Page 3.

2. Park K. Park's textbooks of Preventive and Social Medicine. 17th edition. 2002: 207-215.

3. Park K; Park's textbook of preventive and social medicine, 22nd; 2013: 251-256.

4. Sekhon AS, Singh A, Kaur P, Gupta S. Misconceptions and Myths in the management of animal bite case. Indian $\mathbf{J}$ Community Med. 2002;27(1):9-11.

5. WHO. Weekly Epidemiological record, No 32, 2010.

6. Valekar S, Kshirsagar M, Ashturkar M, Mhaske M, Chawla P, Fernandez K. A cross-sectional study of awareness regarding dog bite and its management in rural community of Maharashtra. Int J Community Med Public Health. 2014;1(1):8.

7. WHO. Animal bites. WHO; Available at: http://www.who.int/mediacentre/factsheets/fs373/en /. Accessed on 3 August 2017.

8. Sudarshan MK, Mahendra BJ, Madhusudana SN, Ashwoath Narayana DH, Rahman A, Rao NSN, et al. An epidemiological study of animal bites in India: results of a WHO sponsored national multicentric rabies. J Commun Dis. 2006;38(1):32-9.

9. Ichhpujani RL, Chhabra M, Mittal V, Singh J, Bhardwaj M, Bhattacharya D, et al. Epidemiology of animal bites and rabies cases in India. A multicentric study. J Commun Dis. 2008;40:27-36.

Cite this article as: Singh A, Agarwal M, Singh A, Katyal R, Joshi HS, Khan S. Knowledge about first aid, wound management and vaccination for the cases of dog bite: a cross-sectional study among the students of a management and technology institute in western Uttar Pradesh. Int J Community Med Public Health 2018;5:280-3. 